Appl. Phys. 13, 107--108 (1977)

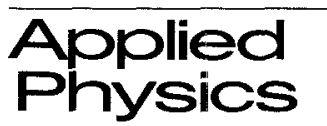

(C) by Springer-Verlag 1977

\title{
Excimer Gas-Discharge Tunable ArF Laser
}

\author{
Yu. A. Kudryavtsev and N. P. Kuzmina \\ Institute of Spectroscopy Academy of Sciences of USSR, Moscow, Podolskii rayon, \\ Akademgorodok, URSS 142092
}

Received 18 November 1976

\begin{abstract}
Intense laser oscillation has been observed from ArF molecules at $1933 \AA$. Excitation of the gas mixture $\mathrm{NF}_{3}: \mathrm{Ar}: \mathrm{He}=1: 55: 630$ at total pressures above $2.1 \mathrm{~atm}$ was produced by a transverse electric discharge. The range of fine tuning was from $1927 \AA$ to $1936 \AA$. An output energy of $0.8 \mathrm{~mJ}$ was measured from a laser pulse $15 \mathrm{~ns}$ in duration.
\end{abstract}

PACS Code : 42.55

Recent works reported on excimer lasers operating on rare-gas monohalides $\mathrm{XeF}[1,2], \mathrm{XeCl}$ [3], $\mathrm{XeBr}$ [4], $\mathrm{KrF}[3,5-7]$, ArF [8]. Excitation in these systems is brought about by a heavy-current beam of relativistic electrons. Of great practical interest are electricdischarge excimer lasers which afford rather high radiation power and high efficiency. It has been also reported that generation can be achieved through excitation by electric discharge in $\mathrm{XeF}[8,9], \mathrm{XeCl}$ [10], $\mathrm{KrF}[11]$.

In this paper we discuss an electric-discharge tunable ArF-laser operating in the vacuum ultraviolet.

\section{Experiment}

Excited $\mathrm{ArF}^{*}$ molecules are formed by the chemical reaction of excited Ar* atoms with the $\mathrm{NF}_{3}$ molecule. Initially the $\mathrm{ArF}^{*}$ molecules are in high vibrational states and, as a result of their collisions with a buffer gas (helium), pass into a lower vibrational level. The lower electron level is repulsive. The operating laser transition is bound-free.

The gas mixture of $\mathrm{He}, \mathrm{Ar}$, and $\mathrm{NF}_{3}$ in the ratio $630: 55: 1$ at the total pressure $2.0 \div 3.5 \mathrm{~atm}$. was excited by a transverse electric discharge with the help of a Blumline line. A line of size $60 \times 36 \mathrm{~cm}$ and capacity $3.8 \cdot 10^{-9} \mathrm{~F}$ was charged by pulses of up to $30 \mathrm{kv}$. The laser cell identical in design with that of the VUV $\mathrm{H}_{2}$-laser [12] was made of glass, its ends tapered at the Brewster angle, the active volume was $36 \times 1.1 \times 0.1 \mathrm{~cm}$. The active zone pre-ionization by displacement current assures charge stability at a high pressure.

The cavity was formed by a diffraction grating of 1200 line $/ \mathrm{mm}$ operating in the third order and a plane translucent aluminum mirror with a reflection coefficient of $30 \%$.

A $1 \mathrm{~m}$-spectrograph with a grating of $1200 \mathrm{line} / \mathrm{mm}$ and a dispersion of $13 \AA / \mathrm{mm}$ was used to measure spectra of spontaneous and laser radiation. The spectra were photographed on UV-2 Schumann film. The iron arc spectrum was used as a reference. The energy of laser radiation was measured with a calibrated thermopile and its duration-with a coaxial photoelement and a time interval meter. The time resolution of the system was not worse than 3 ns.

\section{Results}

Figure 1 shows the spectra of spontaneous and laser radiation. The spontaneous radiation spectrum was produced with a mixture pressure of $1.5 \mathrm{~atm}$ in a cell without cavity, while the laser radiation spectrum was produced for different positions of the grating. The laser line half-width is $2.5 \AA$. The range of fine tuning was from $1927 \AA$ to $1936 \AA$. As the cavity is tuned to the amplification contour peak, the radiation energy equaled $0.25 \mathrm{~mJ} /$ pulse. When the diffraction grating 


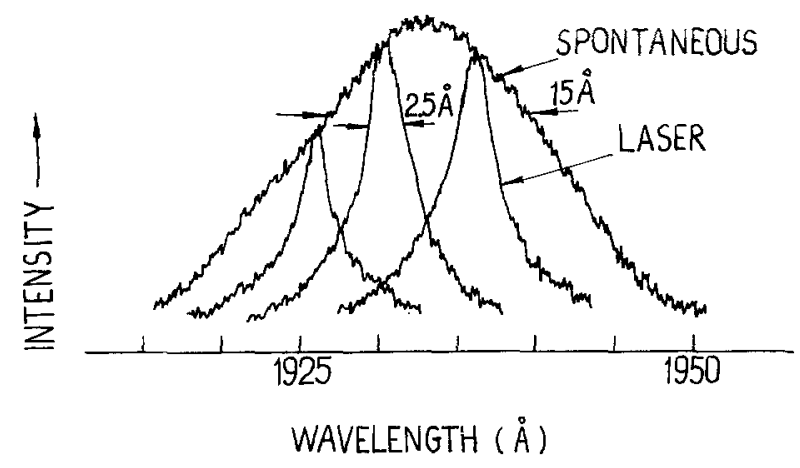

Fig. 1. Spectrum of spontaneous luminescence from a cell without any cavity at $1.5 \mathrm{~atm}$, and spectrum of laser radiation at different positions of the diffraction grating

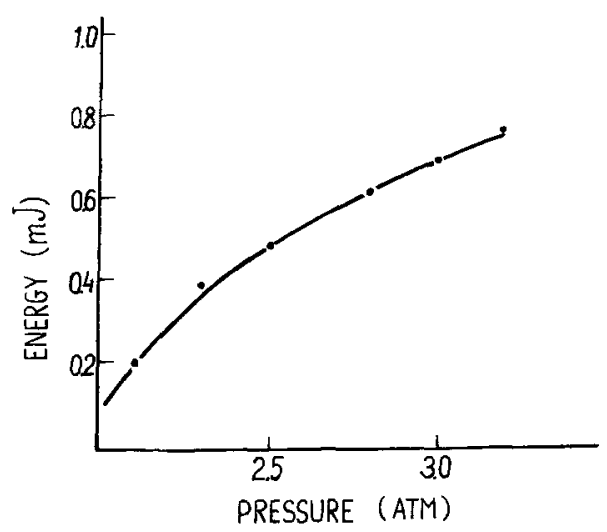

Fig. 2. Dependence of laser radiation energy on active medium pressure. Mixture: $\mathrm{NF}_{3}: \mathrm{Ar}: \mathrm{He}=1: 55: 630$

was replaced by a mirror with the reflection coefficient of $68 \%$, the spectral line half-width increase up to $5 \AA$ and the radiation pulse energy equaled $0.8 \mathrm{~mJ}$. The center of the radiation line falls on $1933 \AA$. When this radiation passes through air, there are three lines of molecular oxygen absorption observed on the spectrogram.
Figure 2 illustrates how generation energy depends on the active medium pressure. Generation appears only at pressures above $2.1 \mathrm{~atm}$ and grows with increasing pressure. Further increase in the pressure, above $3.5 \mathrm{~atm}$, may result in a cell failure.

The pulse half-width was $15 \mathrm{nsec}$ (FWHM). The estimated radiation power equals $50 \mathrm{~kW}$.

The laser operated with a repetition frequency of up to $5 \mathrm{~Hz}$ with no decrease in the peak power. To increase the repetition frequency, it is necessary that operating mixture should be pumped at a high rate. For ArF-laser it is easy to increase the pumping rate since all the components of the gas mixture are comparatively cheap in contrast to other excimer lasers operating on rare-gas monohalides such as $\mathrm{XeF}$ and $\mathrm{KrF}$.

\section{References}

1. C.A. Brau, J.J.Ewing: Appl. Phys. Lett. 27, 435 (1975)

2. E.R.Ault, R.S. Bradford, Jr., M.L. Bhaumik: Appl. Phys. Lett. 27, 413 (1975)

3. J. J.Ewing, C.A.Brau: Appl. Phys. Lett. 27, 350 (1975)

4. S. K.Searles, G. A. Hart: Appl. Phys. Lett. 27, 243 (1975)

5. G.C.Tisone, A.K.Hays, J.M.Hoffman: Opt. Commun. 15, 188 (1975)

6. M.L.Bhaumik, R.S. Bradford, Jr., E.R.Ault: Appl. Phys. Lett. 28, 23 (1976)

7. J.M.Hoffman, A.K.Haus, G.C.Tisone: Appl. Phys. Lett. 28, 538 (1976)

8. R.Burnham, N.W.Harris, N.Djen: Appl. Phys. Lett. 28, 86 (1976)

9. C.P.Wang, H.Mirels, D.G.Sutton, S.N.Suchard: Appl. Phys. Lett. 28, 326 (1976)

10. Yu.A. Kudryavtsev, N.P. Kuzmina: Sov. J. Quantum Electron. 4, $220(1977)$

11. D.G.Sutton, S.N.Suchard, O.L.Gilb, C.P.Wang: Appl. Phys. Lett. 28, 522 (1976)

12. I.N.Knyazev, V.S.Letokhov, V.G. Movshev: IEEE. J. Quantum Electron. QE-11, 805 (1975) 